\title{
FORMAÇÃO DE PROFESSORES DE LÍNGUA BRASILEIRA DE SINAIS: REFLEXÕES SOBRE O IMPACTO DESTA AÇÃO PARA A EDUCAÇÃO
}

\author{
Ana Claudia Balieiro Lodi ${ }^{*}$ \\ Cristina Broglia Feitosa de Lacerda**
}

\begin{abstract}
RESUMO
Este artigo tem como objetivo problematizar aspectos envolvidos na formação de professores de Libras para os diferentes níveis de ensino e as tensões decorrentes para a educação de surdos/educação inclusiva. Em diálogo com os processos históricos/ conceituais relativos à formação de professores, reconhecemos pouco investimento na formação do pedagogo bilíngue; em contrapartida, grande esforço na formação de professores para atuação nos anos finais do ensino fundamental, médio e na educação superior. Questionamos, no entanto, os efeitos desta formação,que enfatiza os conteúdos linguísticos em detrimento dos didático-pedagógicos. Na educação superior, as diferentes leituras quanto aos objetivos da disciplina Libras indicam ser este o espaço privilegiado para a formação dos licenciandos que, futuramente, atuarão com alunos surdos. Conclui-se, neste contexto, que a lógica predominante nas políticas atuais privilegia os princípios da educação inclusiva e não da educação bilíngue para surdos.
\end{abstract}

Palavras-chave: Formação de professores. Língua Brasileira de Sinais. Educação Básica. Educação Superior.

* Doutora em Linguística Aplicada e Estudos da Linguagem pela Pontifícia Universidade Católica de São Paulo. Professora nos Cursos de Licenciatura e do Programa de PósGraduação em Educação do Departamento de Educação, Informação e Comunicação da Faculdade de Filosofia, Ciências e Letras de Ribeirão Preto da Universidade de São Paulo (DEDIC/FFCLRP/USP).E-mail: analodi@ffclrp.usp.br

** Doutora em Educação pela Universidade Estadual de Campinas. Professora do Curso de Licenciatura em Educação Especial e do Programa de Pós-Graduação em Educação Especial do Departamento de Psicologia do Centro de Ciências Humanas da Universidade Federal de São Carlos (DPsi/CECH/UFSCar).E-mail: clacerda@ufscar.br 


\begin{abstract}
This article aims to discuss aspects related to training LIBRAS teachers for different levels of education and the tensions resulting from deaf education/inclusive education. When analyzing the historical/conceptual processes related to teacher training, we find little investment in the training of bilingual educators; on the other hand, there is a great effort to train teachers to work in the final years of elementary and high school and in higher education. However, we question the effects of this training, which emphasizes linguistic contents rather than didactic and pedagogical contents. In higher education, the different ways of understanding the objectives of LIBRAS as a subject matter indicate this is a privileged space for training teachers who will work with deaf students. In conclusion, in this context, the prevailing logic in the implementation of current policies favors the principles of inclusive education and not the bilingual education for deaf people.
\end{abstract}

Keywords: Teacher Training. Brazilian Sign Language. Basic Education. Higher Education.

\title{
Introdução
}

Há mais de uma década a língua brasileira de sinais (Libras) foi "reconhecida como meio legal de comunicação e expressão" (BRASIL, 2002, Artigo $1^{\circ}$ ) das comunidades surdas brasileiras pela Lei $n^{\circ} 10.436 / 02$. Esta legislação, embora não garanta a Libras status de língua oficial do País, assegura o direito legal de uso desta língua por e com as pessoas surdas e dispõe sobre a inclusão do ensino de Libras na educação superior para os cursos de Educação Especial, Fonoaudiologia e Magistério (BRASIL, 2002, Artigo $4^{\circ}$ ). Com a regulamentação desta Lei pelo Decreto Federal $n^{\circ}$ $5.626 / 05$, passa a ser assegurada, às pessoas surdas, a presença desta língua "em todos os níveis, etapas e modalidades de educação, desde a educação infantil até à superior" (BRASIL, 2005, Artigo 14), a fim de que lhes seja garantido, em caráter obrigatório, "o acesso à comunicação, à informação e à educação" (BRASIL, 2005, Artigo 14). Em função disso, o documento dispõe sobre a necessidade da Libras tornar-se objeto de ensino em todos os cursos de formação de professores para a educação básica (BRASIL, 2005, Artigo $3^{\circ}$ ), ampliando, desse modo, o previsto na Lei $n^{\circ} 10.436 / 02$. Dispõe ainda que a formação de docentes para o ensino de Libras (educação básica 
e superior) seja realizada por meio de curso de licenciatura plena em Letras: Libras ou Letras: Libras/língua portuguesa como segunda língua (BRASIL, 2005, Artigo $4^{\circ}$ ), tendo, as pessoas surdas, prioridade para formação nesses cursos (BRASIL, 2005, Artigo 4º Parágrafo único).

Nos doze anos que sucederam a promulgação da Lei $\mathrm{n}^{\circ} 10.436 / 02 \mathrm{e}$ nos nove que seguiram a publicação do Decreto Federal $n^{\circ} 5.626 / 05$, as comunidades acadêmicas que atuavam nos estudos da Libras e defendiam a educação bilíngue para surdos reconheceram, nestes documentos, os primeiros passos em direção a algumas potenciais mudanças relativas à divulgação e ao reconhecimento social da língua das comunidades surdas brasileiras. Acreditou-se ainda que estes documentos poderiam levar a transformações na estrutura educacional brasileira tanto no que diz respeito à educação básica para surdos, que poderia vir a contemplar a Libras como língua de ensino; quanto a superior, pois envolvia a formação de futuros docentes que, mesmo que não fluentes em Libras, poderiam vir a ter conhecimentos sobre as especificidades linguísticas e socioculturais das comunidades surdas do Brasil.

No entanto, apesar do Decreto Federal reconhecer e respeitar os direitos linguísticos, educacionais e culturais das pessoas surdas, poucas mudanças foram sentidas na prática e algumas caminharam em direção oposta ao esperado/disposto na legislação brasileira. Como um dos principais fatores para isso, reconhece-se a manutenção das discussões e políticas relativas à educação de surdos/formação de professores para a educação básica no bojo da política nacional de inclusão da pessoa com deficiência, fazendo com que várias tensões e contradições emerjam (LODI, 2013).

Com a publicação da Política Nacional de Educação Especial na Perspectiva da Educação Inclusiva, em 2008, observa-se, em consonância ao discutido por Lodi (2013), um movimento de desvalorização da Libras, que passa a ganhar caráter instrumental na educação de surdos, distanciando-a, portanto, de seu status linguístico. Neste documento não se prevê seu uso como língua de interlocução professores-alunos no período regular de escolarização e sua presença em sala de aula restringe-se aos tradutores e intérpretes (quando presentes), profissionais com papel e formação não definidos pela Política. O uso da Libras é deslocado para o atendimento educacional especializado, espaço pensado para a complementação da escolarização regular e não como substitutivo ao primeiro. Desse modo, a presença de professores surdos e/ou ouvintes bilíngues, como disposto 
no Decreto, não é discutida, esvaziando-se no movimento de inclusão dos surdos nas salas de aula com ouvintes.

No que se refere à educação superior, apesar dos esforços das instituições para o cumprimento do Decreto no que diz respeito à inclusão da disciplina Libras nos cursos de formação de professores, questionamentos começam a emergir relativos ao perfil do docente e ao papel desta disciplina nos currículos das universidades, determinados, principalmente, pelas contradições que sustentam os dois documentos oficiais: o Decreto Federal $n^{0} 5.626 / 05$ e a Política de Educação Especial.

Frente a esta realidade, este artigo tem como propósito discutir e problematizar alguns aspectos envolvidos no âmbito da formação de professores de Libras para os diferentes níveis de ensino e os efeitos dessa formação no cenário da educação de surdos/educação inclusiva no momento atual. Antes, porém, de aprofundarmos o debate específico sobre este tema, traremos para dialogar com esta discussão alguns aspectos históricos e teóricos da área de formação de professores no Brasil de maneira ampla. Para tecer estas reflexões, tomaremos como base as discussões realizadas por Saviani (2008).

\section{Aspectos históricos e conceituais da formação de professores}

Segundo Saviani (2008), a formação de professores emergiu como exigência e recebeu resposta institucional na Europa, apenas no século XIX, após a Revolução Francesa, em função da ampliação da instrução educacional não apenas para os nobres ou religiosos, mas também para o povo. No entanto, muito antes deste período, já havia universidades, instituídas no século XI, e colégios de humanidades que se expandiram a partir do século XVII. Para atuar nestes espaços, os profissionais formavam-se a partir do princípio do "aprender fazendo", próprio das corporações de ofício, ao mesmo tempo em que a eles era atribuída a responsabilidade de ensinar os conhecimentos que deveriam ser transmitidos pelos professores nas escolas inferiores.

Com a universalização da educação elementar no século XIX, tornou-se necessária a formação de professores em grande escala, fato que determinou a criação das Escolas Normais, encarregadas da preparação de professores para atender o aumento no número de pessoas que passavam, agora, a receber educação. A Escola Normal corresponderia ao que hoje chamamos de 
formação em nível médio e era responsável pela formação de professores para atuar na educação primária; a Escola Normal Superior pela formação de professores que atuariam no nível secundário, menos acessível a grande população. No entanto, com o tempo, a Escola Normal Superior foi se dedicando aos chamados altos estudos - adensamento do conhecimento técnico em uma área específica - e a formação oferecida começou a distanciar-se dos aspectos relativos aos processos didático-pedagógicos. Observa-se assim que, naquela época, começou a delinear-se um cenário que favorecia a compreensão de que um professor da educação primária tinha um status social diferente e menor se comparado com aqueles do nível secundário, na medida em que este último recebia uma formação diferenciada, voltada ao domínio de um campo específico do conhecimento.

Esta maneira de se conceber os professores, influenciou os diferentes momentos que perpassaram a formação para estes profissionais oferecida no Brasil, preocupação que, segundo Saviani (2008), teve início após a independência, quando começou a ser conjecturada a instrução popular. Ao analisar os aspectos relacionados às questões pedagógicas em articulação com as transformações sociais nos últimos dois séculos, o autor distingue seis períodos na história da formação de professores em nosso País.

No primeiro período $(1827$ - 1890), a formação dos professores tornou-se garantida por meio da promulgação da Lei das Escolas de Primeiras Letras; posteriormente, entre 1890 - 1932, este processo formativo, seguindo o modelo europeu, passou então a ser realizado pelas Escolas Normais. Estas, guiadas por coordenadas pedagógico-didáticas, tinham em sua concepção o objetivo de possibilitar aos futuros professores uma formação específica; para isso, era necessária uma reforma nos planos de estudos, concretizada por meio do enriquecimento dos conteúdos curriculares e do estabelecimento de exercícios práticos de ensino. Para se garantir a formação didático-pedagógica dos professores, foi criada, em São Paulo, a Escola-Modelo anexa à Escola Normal, principal inovação da reforma. Entretanto, de forma contrária, o domínio de conteúdos a serem transmitidos às crianças prevaleceu e o preparo didático-pedagógico acabou sendo negligenciado (SAVIANI, 2008).

No período de 1932 - 1939 tem-se início a uma nova fase que se caracterizou pela organização dos Institutos de Educação. Estes, "concebidos como espaços de cultivo da educação encarada não apenas como objeto do ensino, mas também da pesquisa" (SAVIANI, 2008, p. 4), foram inspirados 
pelo ideário da Escola Nova e, portanto, tinham como objetivo a consolidação do modelo didático-pedagógico na formação de professores até então não conseguido pelas Escolas Normais. Nesse sentido, os Institutos foram organizados visando a incorporação das "exigências da pedagogia que buscava se firmar como um conhecimento de caráter científico" (SAVIANI, 2008, p. 5).

No período subsequente, que se estendeu até o ano de 1971, assistiu-se à organização e implantação dos Cursos de Pedagogia e de Licenciatura em nível superior. Buscava-se, por meio dos Cursos de Pedagogia, a formação de docentes para as escolas normais, enquanto os de Licenciatura se ocupavam da formação de professores para as escolas secundárias, responsáveis por ministrar as diferentes disciplinas que compunham o currículo deste nível educacional. Em ambas as experiências, os três primeiros anos eram destinados ao estudo das disciplinas específicas e o último à formação didática, organização que ficou conhecida como "esquema 3 + 1" (SAVIANI, 2008, p. 6). Os cursos normais, por sua vez, foram mantidos em nível secundário e tinham como objetivo a formação do professor para o ensino primário. No entanto, os três cursos existentes dispensavam a exigência da prática, organizando-se a partir de um conjunto de disciplinas de cunho teórico. Esta organização curricular, principalmente nos cursos superiores, resultou em uma formação "fortemente marcada pelos conteúdos culturais-cognitivos, relegando o aspecto pedagógico-didático a um apêndice de menor importância representado pelo curso de didática" (SAVIANI, 2008, p. 7).

Com o golpe militar de 1964, houve adequações nas esferas educacionais, e as escolas normais foram substituídas por habilitações específicas para o magistério, que ficaram a cargo dos cursos de Pedagogia (1971 - 1996). Nessas, previa-se a formação de especialistas para atuarem como diretores de escola, orientadores educacionais, supervisores e inspetores de ensino e, neste contexto, têm início os primeiros cursos de formação de professores para a educação especial em nível superior, como habilitação do curso de Pedagogia. Até este momento, iniciativas voltadas a esta formação específica se davam por meio de cursos de extensão, como o oferecido em 1962, pela Universidade Federal de Santa Maria (DEIMLING, 2013).

Cabe destacar que a organização dos cursos de Pedagogia/habilitações também seguiam o "esquema 3 + 1" discutido por Saviani (2008), ou seja, os três primeiros anos voltavam-se para a formação do pedagogo e o último destinava-se à formação do especialista e, neste contexto, a formação para 
professores da educação especial. A maioria das implantadas no Brasil preocupava-se com a educação de alunos com deficiência intelectual; na área da educação de surdos - habilitação em Educação de Deficientes da Audiocomunicação (Edac) - destaca-se, como pioneiros, a implantada pela Pontifícia Universidade Católica de São Paulo, em 1973, e um ano mais tarde, pela Universidade Federal de Santa Maria (DEIMLING, 2013). Neste período, a formação oferecida aos professores nestes cursos e nos outros iniciados posteriormente, voltava-se para um trabalho oralista e, portanto, não se cogitava (também por desconhecimento da língua de sinais neste período histórico) um trabalho envolvendo o uso da Libras.

A partir de 1980, a maioria das instituições direcionou a formação dos pedagogos para a educação infantil e para as séries iniciais do $1^{\circ}$ grau; no entanto, com o fim do governo militar e a partir da promulgação da nova Lei de Diretrizes e Bases da Educação Nacional (LDBN), em 1996, passaram a figurar no cenário nacional os Institutos Superiores de Educação e as Escolas Normais Superiores como espaços também de formação de pedagogos. Estas instituições, no entanto, acabaram promovendo uma formação mais barata, por meio de cursos de curta duração, fato que repercutiu nas "novas diretrizes curriculares do Curso de Pedagogia homologadas em abril de 2006" (SAVIANI, 2008, p. 8).

Observa-se, neste breve histórico, que o processo de formação docente passou por contínuas transformações caracterizadas por sucessivas descontinuidades nas propostas/práticas realizadas. Em todo o percurso, nota-se a coexistência de pelos menos dois modelos teóricos, que se contrapõem. Para o primeiro, denominado por Saviani (2008) modelo dos conteúdos culturais-cognitivos, "a formação dos professores se esgota na cultura geral e no domínio específico dos conteúdos da área de conhecimento correspondente à disciplina que o professor irá lecionar" (SAVIANI, 2008, p. 10); a formação pedagógico-didática era decorrente do domínio dos conteúdos, do conhecimento logicamente organizado, sendo adquirida na própria prática docente ou mediante mecanismos de 'treinamento em serviço'. O segundo modelo, pedagógico-didático, "considera que a formação propriamente dita dos professores só se completa com o efetivo preparo pedagógico-didático" (SAVIANI, 2008, p. 10); portanto, além da cultura geral e da formação específica na área de conhecimento correspondente, a instituição formadora deverá assegurar, de forma deliberada e sistemática (por meio da organização 
curricular), a preparação pedagógico-didática sem a qual não estará, em sentido próprio, formando professores.

Esta concepção referente à formação de professores, longe de estar resolvida, permanece na contemporaneidade. É o caso do predomínio do primeiro modelo na estruturação dos cursos de licenciaturas de nossas universidades. Ou seja, mantém-se ainda a ideia de que para ser considerado um bom professor, o que conta é o domínio das áreas específicas de conhecimento. Para Saviani (2008), ao prevalecer na universidade a centralização dos conteúdos culturais-cognitivos para a formação de professores licenciados, negligencia-se o ensinar como ensinar, "em consequência, não deixa de estar presente também no ethos dos professores universitários brasileiros uma certa depreciação do aspecto pedagógico" (SAVIANI, 2008, p. 11).

Com o passar dos anos, o modelo pedagógico-didático ganhou espaço na organização dos currículos formativos por via legal, tornando-se componente curricular obrigatório também nos cursos de licenciaturas. No entanto, esta obrigatoriedade nem sempre altera a organização curricular dos cursos que, muitas vezes, mantem-se a partir do esquema $3+1$, esvaziando, desse modo, os sentidos pretendidos para a formação de professores. Outro aspecto que contribui para esta cisão entre o que é específico e a formação pedagógica, diz respeito ao fato de, frequentemente, as disciplinas pedagógicas estarem a cargo das Faculdades e/ou Departamentos de Educação, enquanto as disciplinas específicas mantem-se sob a responsabilidade dos departamentos exclusivos, gerando uma organização que não favorece o diálogo entre quem ensina o conteúdo e quem ensina a forma de fazer este conteúdo chegar ao aprendiz. A formação do professor, desse modo, fica fragmentada, cabendo ao próprio aluno, futuro professor, a integração dos conhecimentos que foram apresentados de forma desconectada.

A não articulação entre os modelos dos conteúdos culturais-cognitivos e de formação pedagógico-didática que persiste historicamente indica que, até hoje, as políticas de formação de professores não conseguiram "estabelecer um padrão minimamente consistente de preparação docente para fazer face aos problemas enfrentados pela educação escolar em nosso país" (SAVIANI, 2008, p. 9). Esta maneira de se pensar a formação docente repercute, diretamente, nos cursos de formação de professores de Libras, tensão esta que passamos a nos dedicar. 


\section{A formação de professores para o ensino de Libras e seus reflexos para a educação de surdos}

Em um paralelo entre o histórico de formação docente de forma geral e especificamente para a formação dos professores de Libras, é possível observar que, assim como no início das discussões no século XVII na Europa, aqueles que se dedicavam às práticas de ensino de Libras no Brasil, iniciadas em meados da década de 1980, atuavam na perspectiva do 'aprender fazendo' (NEVES, 2011).

Foi na década de 1990 que a formação deste professor começou a ser pensada (ainda não em nível superior) e metodologias específicas começaram a ser delineadas considerando a materialidade visual, gestual e espacial desta língua. Esta formação inicial esteve sob a responsabilidade da Federação Nacional de Educação e Integração dos Surdos (Feneis) que, em parceria com o Ministério da Educação (MEC), promoveu a formação de instrutores de Libras (nomenclatura utilizada para professores de Libras com formação em nível médio, conforme o Decreto $\mathrm{n}^{\circ} 5.626 / 05$ ), realizada por meio de cursos de curta duração. Estes cursos eram ministrados preferencialmente para surdos, mas ouvintes também se beneficiaram desta formação. Interessante observar que a formação oferecida aos instrutores, da mesma forma que os processos discutidos por Saviani (2008) para a formação de professores, não tinham como objetivo a preparação didático-pedagógica do profissional para o desenvolvimento da prática de ensino da língua: privilegiava-se o conhecimento da língua, ou mais especificamente, o domínio que o profissional possuía em relação ao uso da Libras, sem voltar-se para uma reflexão sobre a língua ou sobre como ensiná-la.

Nesta mesma década, apoiado por estudos e pesquisas realizadas no exterior (em especial, Suécia, Estados Unidos e Uruguai), tem-se início o movimento em defesa da necessidade de implantação da educação bilíngue para surdos, na qual a Libras assume papel central para todos os processos de ensino e de aprendizagem escolar. Entra em cena então, agora como ator principal, a figura do professor surdo (mesmo sem formação superior), considerado como interlocutor privilegiado para a imersão dos alunos surdos na língua de sinais, "interferindo ideologicamente, por meio dela, nos padrões culturais e de interpretação de mundo fundadas nas relações com a linguagem" (LODI, 2004, p. 29). Neste contexto, algumas escolas 
de surdos começaram a contratar instrutores surdos para atuarem no espaço escolar, como forma de garantir, aos alunos, seu direito à apropriação da Libras como primeira língua, ao mesmo tempo em que ministravam cursos de Libras (ainda com base na proposta desenvolvida pela Feneis/MEC) aos professores regentes da escola (ouvintes) para que pudessem melhor conduzir os processos educacionais dos alunos nesta língua.

Foi somente nos anos 2000, com a promulgação da Lei n ${ }^{\circ}$ 10.098/00, que os surdos passaram a ingressar na educação superior, a partir do momento em que lhes é assegurada a presença de tradutores e intérpretes de Libras - língua portuguesa em sala de aula. Destaca-se, neste processo, que nesta nova perspectiva educacional que se abre aos surdos, uma quantidade significativa deles ingressa em cursos de Pedagogia, a fim de se tornarem, futuramente, professores regentes nos processos de escolarização de crianças surdas, em especial nas escolas para surdos. No ano de 2005, com a publicação do Decreto Federal n ${ }^{0} 5.626$, passa então a ser exigida a formação do professor de Libras em nível superior para atuar nas séries finais do ensino fundamental, no ensino médio e na educação superior. Em igualdade ainda ao que é previsto para professores de outras línguas, esta deve ocorrer em cursos de graduação de licenciatura plena em Letras: Libras ou Letras: Libras/língua portuguesa como segunda língua (BRASIL, 2005, Artigo $4^{\circ}$ ).

Para o ensino da Libras na educação infantil e nos anos iniciais do ensino fundamental prevê-se a formação em cursos de Pedagogia ou normal superior (BRASIL, 2005, Artigo $5^{\circ}$ ), abrindo-se ainda a possibilidade, para atuação nestes níveis de ensino, de uma formação realizada em nível médio, que pode vir a ser oferecida na modalidade normal ou em cursos de educação profissional, de formação continuada oferecidos por instituições de educação superior, por instituições credenciadas por secretarias de educação ou ainda por organizações da sociedade civil que representem as comunidades surdas, como no caso da Feneis (BRASIL, 2005, Artigos $5^{\circ}$ e $6^{\circ}$ ).

Há, desse modo, pela primeira vez na história da legislação brasileira, o reconhecimento da Libras também como objeto de ensino e, para isso, a equiparação da formação exigida entre profissionais ouvintes e surdos para a atuação na educação básica. No entanto, ao se permitir uma formação do profissional que irá atuar no ensino de Libras para estudantes dos anos iniciais de escolarização em nível médio, observa-se que, assim como na formação de instrutores realizadas pela Feneis, o foco formativo recai, no- 
vamente, sobre o domínio da língua e das diferentes linguagens que lhe são constitutivas, para uso nos diferentes espaços sociais. Nesta lógica, pouca ou nenhuma atenção é dada aos processos didático-pedagógicos, da mesma forma que, como discutido por Saviani (2008), esta é também a compreensão majoritária dos cursos de licenciatura/Pedagogia.

Este mesmo Decreto Federal dispõe ainda sobre a obrigatoriedade da inclusão da disciplina curricular Libras em todos os cursos de formação de professores: cursos de licenciatura nas diferentes áreas do conhecimento, curso normal oferecidos em nível superior e médio e cursos de Pedagogia que não se constituam licenciaturas. A implantação desta disciplina nas matrizes curriculares dos cursos contribuiu para a abertura de um novo mercado de trabalho para os surdos, que passaram a compor o corpo docente das Instituições de Educação Superior, públicas e privadas. E com a proximidade da data limite para que a disciplina Libras seja implantada em 100\% dos cursos de formação de professores oferecidos (dezembro de 2015), gradativamente a demanda por professores para assumir esta disciplina aumenta significativamente.

Considerando as particularidades implicadas na formação do professor para atuação na educação básica e na educação superior, trataremos as questões implicadas nos processos formativos de forma separada.

\section{A formação do professor de Libras para atuar na educação básica}

Com a publicação do Decreto Federal $n^{0} 5.626 / 05$, esperava-se que a formação de professores bilíngues formados em Pedagogia ou em curso normal fosse se tornar objeto de atenção, dado que estes profissionais, de importância ímpar para os processos educacionais, seriam os responsáveis por possibilitar a apropriação da Libras como primeira língua, pelo ensino dos conteúdos pedagógicos e do português como segunda língua para os alunos surdos. Estes processos são imprescindíveis para a implementação de uma educação em uma perspectiva bilíngue para surdos (tal como defendida pelo Decreto, pelas comunidades surdas do Brasil e por pesquisadores da área da educação de surdos) e base para um estudo da Libras como disciplina curricular nos anos subsequentes, foco da formação dos professores licenciados em Letras: Libras. Apesar disso, no entanto, para a educação infantil e anos iniciais do ensino fundamental, a formação que tem predominado é 
aquela realizada por meio de cursos de extensão ou de especialização em Libras de curta duração, oferecidos por instituições de educação superior, além daqueles oferecidos por organizações da sociedade civil.

Em diálogo com as ponderações realizadas por Saviani (2008), observase que também na formação de docentes de Libras, o pouco investimento realizado com vistas à formação do pedagogo bilíngue torna-se um indicativo da manutenção de uma visão que atribui, aos professores que atuam na educação infantil e anos iniciais do fundamental, status social menor se em comparação com aqueles que trabalharão nos anos finais do ensino fundamental e ensino médio. Entretanto, ao se considerar a particularidade linguística dos surdos, essa opção acaba por levar a consequências nefastas, pois a escola, para este grupo social, torna-se o lugar privilegiado para se garantir o desenvolvimento linguístico dos alunos, para a constituição de suas subjetividades a partir da diferença linguística, social e cultural e, portanto, para todo o processo de escolarização (LODI, 2012; LODI; ROSA; ALMEIDA, 2012). Sem a presença de profissionais bilíngues neste período, os surdos, uma vez mais, estão sendo privados da possibilidade de apropriação da Libras como primeira língua (marca de toda a história da educação de surdos no Brasil).

De forma inversa, entretanto, logo no ano seguinte à publicação do Decreto ${ }^{\circ} 5.626 / 05$ é ofertado, pela primeira vez no Brasil, o curso de licenciatura em Letras: Libras pela Universidade Federal de Santa Catarina (UFSC). Esse, tendo como objetivo principal a formação de professores de Libras para a educação básica (anos finais do ensino fundamental e ensino médio) e superior e seguindo as determinações do Decreto Federal, privilegiou a matrícula de estudantes surdos. No decorrer dos anos que sucederam ao oferecimento do primeiro Curso Letras: Libras na modalidade a distância pela UFSC, poucas universidades implantaram cursos similares. Nos últimos anos, no entanto, houve um novo investimento do Governo Federal, por meio do Plano Nacional dos Direitos da Pessoa com Deficiência - Viver sem Limite, lançado no dia 17 de novembro de 2011 (Decreto $n^{\circ} 7.612$ ), e novos cursos de Letras: Libras, nas modalidades licenciatura e bacharelado, estão sendo implantados. Dado o caráter recente destes cursos, não é possível, neste momento, uma avaliação acerca da formação que está sendo (ou será) oferecida aos docentes em processo formativo.

Entretanto, em consonância com o discutido por Saviani (2008, p.11), 
reconhecemos que nossas universidades, por indução do Estado, tendem a "se unificar estruturalmente sob o ordenamento comum e com os mesmos currículos formativos". Nesse sentido, o primeiro curso de licenciatura em Letras: Libras oferecido tem sido a base para a proposição e implantação da maioria dos novos, fato que determina a hegemonia de um pensamento único sobre o perfil que se pretende formar como professor de Libras. Nestes, a posição dominante de organização curricular centra-se, predominantemente, nos conteúdos específicos sobre a Libras, dispensando (ou negligenciando) a preocupação com o preparo para a prática didático-pedagógica. Explica-se e justifica-se, por esta lógica, o significativo predomínio dado aos conteúdos relativos à linguística da língua brasileira de sinais em detrimento daqueles que envolvem uma formação para a prática e para a atuação nos espaços educacionais nestes cursos (ALBRES, 2013; PIRES, 2014).

Em diálogo com as reflexões do professor Saviani (2008), ponderamos que nossas universidades têm privilegiado o modelo dos conteúdos culturais cognitivos na formação dos professores, e nesta mesma lógica os cursos de professores de Libras, a formação oferecida ao futuro professor dirige-se para o 'saber bem Libras' (domínio e fluência), 'saber sobre a Libras' (conhecimento sobre aspectos linguísticos), ter conhecimentos sobre desenvolvimento e aprendizagem de pessoas surdas e sobre os Estudos Surdos. Neste contexto, o pouco diálogo estabelecido com o segundo modelo - pedagógico-didático -, desloca o foco da formação do saber desenvolver práticas que possibilitem a apropriação da Libras pelos estudantes para o ensinar a gramática da língua, seja na educação básica ou superior (disciplina oferecida nos cursos de formação de professores).

Em nosso entendimento, e em consonância com os argumentos anteriormente apresentados por Saviani (2008), o ideal seria, então, que a formação oferecida aos futuros professores de Libras articulasse os dois modelos. Esta articulação, entretanto, precisaria ser criativa, já que se trata de ensinar conhecimentos (a Libras e as metodologias implicadas neste ensino) que ainda estão sendo estudados e construídos, dado o caráter relativamente recente de estudos sobre a Libras (iniciados no final da década de 1980) para populações distintas. Neste sentido, reconhecemos que a formação de professores de Libras ainda se constitui um desafio complexo, pois não temos, até o momento, um saber significativo acumulado sobre este fazer (ALBRES, 2013). 
Tem-se, assim, a primeira tensão trazida para ser refletida neste artigo.

Ao olharmos para a presença de licenciados em Letras: Libras na educação básica, logo professores formados para atuar nos anos finais do ensino fundamental e médio, temos que considerar ainda alguns impasses decorrentes da atual Política Nacional de Educação Inclusiva, que indica que todos os alunos - quaisquer que sejam suas características linguísticas, sociais e culturais - devam estar preferencialmente matriculados nas redes regulares de ensino e nelas receber o atendimento educacional adequado às suas necessidades (BRASIL, 2008). Nesse sentido, ao focalizarmos a realidade do Estado de São Paulo, hoje assistimos a inclusão de uma expressiva maioria de alunos surdos incluídos em salas de aula com ouvintes. Destes, pouco dominam Libras como primeira língua, reflexo de uma organização educacional anterior (educação infantil e anos iniciais do ensino fundamental) que não privilegia o pedagogo bilíngue que, teoricamente, deveria ministrar aulas em Libras (LODI, 2013).

Soma-se a isso o deslocamento do ensino em Libras para os espaços de atendimento educacional especializado - AEE (LODI, 2013), realizado por professores que não necessariamente sabem Libras ou conhecem metodologias de ensino pensadas nesta língua. Acrescenta-se ainda o fato de os professores especialistas serem em sua totalidade ouvintes. Portanto, questiona-se o sentido de se formar professores licenciados para estes níveis de ensino e, principalmente, a partir de um modelo que pouco discute o fazer pedagógico considerando a atual Política Nacional de Educação.

Neste contexto, pensando em experiências em que o professor surdo licenciado, hipoteticamente, assuma o espaço do AEE, questionamos ainda se o conhecimento linguístico é aquele a ser privilegiado com os alunos surdos, considerando as poucas experiências e interações linguísticas (em Libras) que lhes foi propiciada nos anos iniciais de escolarização, prática que desrespeita o direito dos alunos surdos de se apropriarem da Libras como primeira língua.

Nova tensão pode ser vislumbrada então ao se colocar em diálogo o disposto pelo Decreto Federal no 5.626/05 e as determinações da Política Nacional de Educação Inclusiva. 


\section{A formação do professor de Libras para atuar na educação superior}

Ao focalizarmos a atuação dos professores licenciados em Letras: Libras para docência na educação superior, novas ponderações merecem destaque. Com a exigência de implantação progressiva da disciplina Libras nos cursos de formação de professores, os debates tornaram-se mais intensos e voltaram-se para os objetivos desta disciplina, considerando que a maioria das instituições de educação superior destina uma carga horária insuficiente para o ensino desta língua. Levantaremos três argumentos que têm sido utilizados atualmente nas reflexões sobre esta prática.

O primeiro deles considera que apesar da reduzida carga horária destinada à disciplina, o mínimo contato com a Libras é benéfico aos futuros professores da educação básica, pois esta disciplina constitui-se em uma oportunidade para eles conhecerem as especificidades linguísticas da Libras, seu valor e sua complexidade, contribuindo para uma mudança de postura quando receberem pessoas surdas como seus alunos.

O segundo advoga a necessidade de se usar o espaço desta disciplina para possibilitar reflexões sobre: a) o ser surdo, alterando-se a visão patológica que ainda predomina nas esferas sociais para um olhar para as pessoas surdas a partir de sua condição sociocultural e bilíngue; b) as particularidades do aluno surdo no que diz respeito à sua impossibilidade de acesso à linguagem oral da língua portuguesa e dificuldades de aprendizagem da linguagem escrita do português, caso este processo não seja pensado a partir de metodologias de ensino de segunda língua; c) a importância de serem revistas as tradicionais práticas de ensino que, por serem voltadas também aos alunos surdos, deveriam levar em consideração o fato desses estudantes utilizarem uma língua visual, gestual e espacial e d) as políticas de educação de nosso País, a fim de se construir uma leitura crítica sobre a educação inclusiva. Nesse sentido, a aprendizagem da língua não se constitui o único foco da disciplina e divide espaço com reflexões no campo da Educação relativas à importância da Libras para os processos educacionais de estudantes surdos.

O terceiro e último argumento defende a impossibilidade do ensino da Libras no âmbito de uma disciplina acadêmica e, portanto, o espaço a ela destinado deveria envolver apenas discussões voltadas à conscientização dos futuros professores sobre as especificidades linguísticas, socioculturais 
e educacionais das comunidades surdas, abordadas no conjunto de temas implicados no campo da educação especial.

Essa diversidade de compreensões sobre os objetivos da disciplina Libras tem implicações diretas nos diferentes modos de sua implementação e reflete, diretamente, no perfil e na maneira de se entender a formação necessária para ser professor de Libras na educação superior. Independente da opção feita pela instituição ou pelo próprio professor, vê-se que conhecimentos outros que transcendem o estudo gramatical/linguístico da Libras, priorizados na formação inicial, são trazidos para este espaço.

Soma-se a isso o fato de não apenas na Política Nacional de Educação, mas também no Decreto $n^{0} 5.626 / 05$ ser prevista, nas séries finais do ensino fundamental e ensino médio - onde atuam os professores licenciados - a presença de tradutores e intérpretes de Libras - língua portuguesa (TILS). Ou seja, quando o aluno surdo for matriculado na rede regular de ensino, ele deverá ser acompanhado para auxiliar seu acesso aos conteúdos pedagógicos por um TILS, já que o professor regente precisará conduzir suas aulas em português. Neste modelo, o professor regente se beneficia dos conhecimentos em Libras obtidos em sua formação inicial, no sentido de melhor compreender a situação vivenciada pelo aluno surdo, e ainda para sua sensibilização em relação à preparação de suas aulas, visando atender adequadamente este aluno (FERREIRA; ZAMPIERI, 2009), mas muito do sucesso de sua organização e docência estará ligado à parceria que este professor pode desenvolver com o TILS no sentido de melhor atender às necessidades do aluno surdo (LACERDA, 2009). Assim, para o professor regente, saber trabalhar em parceria e compreender a atuação do TILS é tão importante quanto ter conhecimentos básicos de Libras e/ou apenas sobre a organização estrutural da língua.

Parece claro que não podemos pensar na disciplina de Libras ofertada na educação superior como o lugar no qual todas as questões formativas relativas à educação de surdos serão contempladas; contudo, este tem sido o espaço privilegiado de atuação de professores surdos e a oportunidade de intervir, em alguma medida, com aqueles que serão (potencialmente) os futuros professores de surdos. 


\section{Tecendo algumas reflexões: tensões políticas envolvendo a formação de professores de Libras}

Muitos aspectos poderiam aqui ser levantados como objeto de reflexão, no entanto, frente aos limites impostos na redação de um artigo, tornou-se necessária a realização de algumas escolhas. Optamos, assim, por buscar refletir sobre a formação que hoje tem sido oferecida nos cursos de licenciatura em Letras: Libras com discussões envolvendo a formação de professores de maneira geral. Procuramos também trazer algumas tensões e as implicações de uma disciplina de Libras para a educação de surdos ao se considerar a priorização dada pelo governo brasileiro à implantação de cursos de licenciatura se em comparação ao reduzidíssimo investimento que vem sendo realizado no sentido de oferecimento de cursos de Pedagogia Bilíngue, fato que traz implicações significativas e preocupantes para a educação de surdos em nosso País.

Os debates na área da educação de surdos apontam para a centralidade da Libras e a necessidade de interações nesta língua, o mais precocemente possível às crianças surdas, de modo a criar condições para que elas se desenvolvam plenamente (LODI; ROSA; ALMEIDA, 2012; MOURA, 2013). Assim, seria de se esperar que os principais investimentos estivessem na criação de cursos de Pedagogia Bilíngue e na circulação da Libras nas unidades de ensino da educação básica, logo, principalmente, na educação infantil e séries iniciais do ensino fundamental. O foco então estaria na formação de professores pedagogos bilíngues - preferencialmente surdos - que atuariam como docentes, interagindo em Libras como seus alunos surdos. Todavia, esta não é a realidade e, ainda hoje, existe apenas um curso de Pedagogia Bilíngue com egressos já formados ${ }^{1}$, sendo uma experiência restrita a um único estado da federação.

Infere-se, assim, que os investimentos públicos privilegiam a lógica da educação inclusiva - e não as bases da educação bilíngue como ingenuamente poderia ser pensado em um primeiro olhar: criam-se cursos de formação de professores de Libras, dando-se preferência para a formação de professores surdos; a comunidade surda se sente contemplada com um curso de formação

1 Curso de Formação de Pedagogos Bilíngues, presencial, ofertado pelo Instituto Nacional de Educação de Surdos (INES), no Rio de Janeiro - RJ, com início em 2008. 
que valoriza sua língua e que abre a possibilidade de seu ingresso no ensino superior; consequentemente, condições para que surdos atuem como docentes do magistério superior são propiciadas, alterando significativamente seu acesso a este nível de ensino. Os surdos passam a ser discentes em maior número e a ser docentes - o que era antes quase inalcançável.

Todavia, o projeto necessário de implantação de uma educação de surdos numa perspectiva bilíngue permanece longínquo apesar de todas estas ações, porque as políticas públicas privilegiam o funcionamento inclusivo, monolíngue, sem qualquer compromisso com o desenvolvimento da Libras junto aos alunos surdos, principalmente aqueles mais jovens. $\mathrm{O}$ professor surdo com formação em nível superior não esta atendendo estes alunos que seriam os que têm maior urgência em participarem de vivências em Libras - prática que poderia impactar fortemente o processo educacional e o desenvolvimento dos estudantes surdos. Entende-se, desse modo que, para a educação básica, a Libras está prevista como língua coadjuvante e, em alguns documentos, apontada como restrita aos AEEs (LODI, 2013).

Há, desse modo, um favorecimento do funcionamento inclusivo, no sentido de trazer algum conhecimento sobre a Libras para o professor regente para que este não se "apavore" com a presença de alunos surdos, fazendo parecer que o aluno surdo será bem recebido pelo sistema e que isso tornará sua educação "resolvida". Mas na verdade o que se observa é que o aprendiz surdo, aluno da educação básica, em nenhum momento é alvo da política que se enuncia como de atenção à educação de surdos.

Assim, podemos entrever uma forte contradição no modo de implementar a política educacional no que diz respeito às prioridades de formação de professores, já que, ao defender a organização de oferta de uma educação bilíngue para o aluno surdo, apoia-se intensamente a formação de professores surdos para um atendimento inclusivo, sem favorecer efetivamente sua participação na escola, e a valorização e a aprendizagem da Libras nos níveis educacionais onde ela seria mais necessária - na educação básica de alunos surdos - não tem ocorrido.

Contudo, esta mesma política colaborou para que o quadro de docentes universitários surdos crescesse muito. Estes docentes universitários podem preparar o ambiente acadêmico para a ampliação de estudos e avanços na área da educação de surdos, desde que esta formação seja também privilegiada. É fundamental usar este espaço político-acadêmico para criar novos espaços 
de formação e reflexão que levem a um modelo formativo e de educação de surdos novo, que pode ser gerado também a partir da universidade que temos hoje. São contradições postas pelas ações políticas que merecem análise, reflexão e novas ações visando construir uma educação de qualidade em nosso País, em todos os segmentos.

Desse modo, em nossa avaliação, o foco destas ações, longe de estar no contribuir para a aceitação social/educacional dos surdos por intermédio da Libras e, portanto, na materialização da educação bilíngue para surdos, parece estar na consolidação de um projeto de educação inclusiva pouco comprometido com as necessidades efetivas dos surdos em seu processo educacional. E assim, para a consolidação deste projeto, faz sentido "preparar" todo e qualquer futuro professor da educação básica para o atendimento de alunos surdos, ainda que muitos deles talvez não tenham em seu percurso docente a oportunidade de ter um aluno surdo.

Os caminhos da formação do professor de Libras na licenciatura ainda precisam sofrer intervenções profundas quando se pretende que este professor também seja responsável pelo ensino de Libras para alunos surdos na educação básica. Nesse sentido, é fundamental refletir sobre uma organização curricular que não privilegie apenas os conhecimentos sobre aspectos linguísticos, mas também aqueles relativos aos aspectos didáticos-pedagógicos, buscando não repetir erros já discutidos no campo da formação de professores de maneira ampla.

Além disso, mostra-se necessário o incentivo a pesquisas que ampliem os conhecimentos que hoje temos sobre a Libras e sobre como ensiná-la nos diferentes níveis de ensino, buscando consolidar um campo de conhecimento que efetivamente contribua para a formação do aluno surdo.

\section{Referências}

ALBRES, N. A. Relações dialógicas entre professores surdos sobre o ensino de Libras. 2013. 236f. Tese (Doutorado em Educação Especial). Centro de Educação e Ciências Humanas, Universidade Federal de São Carlos, São Carlos, 2013.

BRASIL. Lei n. 10.436 de 24 de abril de 2002. Dispõe sobre a Língua Brasileira de Sinais e dá outras providências. Brasília, DF, 25 abr. 2002. Disponível em: <http://www.planalto.gov.br/ccivil_03/leis/2002/110436. htm>. Acesso em: 10 Abr. 2012. 
BRASIL. Decreto n. 5.626, de 22 de dezembro de 2005. Regulamenta a Lei n. 10.436, de 24 de abril de 2002. Dispõe sobre a Língua Brasileira de Sinais - Libras, e o art. 18 da Lei $\mathrm{n}^{\circ} 10.098$, de 19 de dezembro de 2000. Brasília, DF, 23 dez. 2005. Disponível em: $<$ http://www.planalto.gov.br/ccivil_03/_ato2004-2006/2005/decreto/d5626.htm>. Acesso em: 10 abr. 2012.

BRASIL. Política Nacional de Educação Especial na Perspectiva da Educação Inclusiva. Brasília: MEC/SEESP, 2008. 15 p. Disponível em: <http:// portal.mec.gov.br/seesp/arquivos/pdf/politica.pdf $>$. Acesso em: 10 abr. 2012.

BRASIL. Decreto n. 7.612 de 17 de novembro de 2011. Institui o Plano Nacional dos Direitos da Pessoa com Deficiência - Plano Viver sem Limite. Brasília, DF, 18 nov. 2011. Disponível em: <http://www.planalto.gov.br/ccivil_03/_Ato2011-2014/2011/Decreto/D7612.htm>.Acesso em: 10 jul. 2014.

DEIMLING, N. N. N. A educação especial nos cursos de pedagogia: considerações sobre a formação de professores para a inclusão escolar. Educação Unisinos, São Leopoldo, v. 17, n. 3, p. 238 - 249, set./dez. 2013. Disponível em <http://revistas.unisinos.br/index.php/educacao/article/viewFile/ edu.2013.173.08/3815>. Acesso em: 10 Fev. 2014.

FERREIRA, M. C. C.; ZAMPIERI, M. A. Atuação do professor ouvinte na relação com o aluno surdo: relato de experiência nas séries iniciais do ensino fundamental. In: LODI, A. C. B.; LACERDA, C. B. F. de (Org.). Uma escola, duas línguas: letramento em língua portuguesa e língua de sinais nas etapas iniciais de escolarização. Porto Alegre: Mediação, 2009. p. 99 - 112.

LACERDA, C. B. F de. Intérprete de Libras: em atuação na educação infantil e no ensino fundamental. Porto Alegre: Mediação/FAPESP, 2009.

LODI, A. C. B. A leitura como espaço discursivo de construção de sentidos: Oficinas com surdos. 2004. 282 f. Tese (Doutorado em Linguística Aplicada e Estudos da Linguagem), Pontifícia Universidade Católica de São Paulo, São Paulo, 2004.

LODI, A. C. B. Desenvolvimento de linguagem e apropriação da Libras como primeira língua por crianças surdas e práticas de letramento. In: GIROTO, C. R. M.; MARTINS, S. E. S.de O.; BERBERIAN, A. P. (Org.). Surdez e educação inclusiva. São Paulo: Cultura Acadêmica/ Marília: Oficina Universitária, 2012. p. $13-35$. 
LODI, A.C. B. Educação bilíngue para surdos e inclusão segundo a Política Nacional de Educação Especial e o Decreto n ${ }^{0}$ 5.626/05. Educ. Pesqui.,São Paulo, v. 39, n. 1, p. $49-63,2013$.

LODI, A. C. B.; ROSA, A. L. M.; ALMEIDA, E. B.de. Apropriação da Libras e o constituir-se surdo: a relação professor surdo-alunos surdos em um contexto educacional bilíngue. ReVEL, v. 10, n. 19, p. 1 - 20, 2012. Disponível em: $<$ http://www.revel.inf.br/files/0cfd4d051631c1ba66ec76d39d537ac8.pdf $>$. Acesso em: 12 set. de 2014.

MOURA, M. C. de. Surdez e linguagem. In: LACERDA, C. B. F.; SANTOS, L. F. dos. (Org.). Tenho um aluno surdo, e agora? Introdução à Libras e educação de surdos. v. 1. São Carlos: EdUFSCar, 2013. p. 13 - 26.

NEVES, S.L.G. Análise da eficácia e aplicabilidade de dinâmicas para ensino de língua brasileira de sinais para alunos ouvintes. 2011. 89f. Dissertação (Mestrado em Educação), Faculdade de Ciências Humanas, Universidade Metodista de Piracicaba, Piracicaba. 2011.

PIRES, V. de O. D. O processo de construção do letramento acadêmico em língua portuguesa por surdos universitários. 2014. 174f. Tese (Doutorado em Linguística Aplicada), Escola de Indústria Criativa: Comunicação, Design e Linguagens. Universidade do Vale do Rio dos Sinos, São Leopoldo, Rio Grande do Sul.

SAVIANI, D. Formação de professores: aspectos históricos e teóricos do problema no contexto brasileiro. In: ASSOCIAÇÃO NACIONAL DE PÓSGRADUAÇÃO E PESQUISA EM EDUCAÇÃO, 31., 2008, Caxambu. [Anais eletrônicos...]. Disponível em: $<$ http://31reuniao.anped.org.br/5trabalhos_encomendados/trabalho\%20encomendado $\% 20-\% 20$ gt $15 \% 20-\% 20$ dermeval\%20saviani.pdf $>$. Acesso em: 10 jul. de 2014.

Data de registro: $13 / 04 / 2015$

Data de aceite: $26 / 08 / 2015$ 